This item was submitted to Loughborough's Research Repository by the author.

Items in Figshare are protected by copyright, with all rights reserved, unless otherwise indicated.

\title{
Maximal dismounts from high bar
}

PLEASE CITE THE PUBLISHED VERSION

PUBLISHER

(C) Elsevier

VERSION

AM (Accepted Manuscript)

LICENCE

CC BY-NC-ND 4.0

\section{REPOSITORY RECORD}

Hiley, Michael J., and Maurice R. Yeadon. 2019. "Maximal Dismounts from High Bar”. figshare. https://hdl.handle.net/2134/6051. 
This item was submitted to Loughborough's Institutional Repository (https://dspace.lboro.ac.uk/) by the author and is made available under the following Creative Commons Licence conditions.

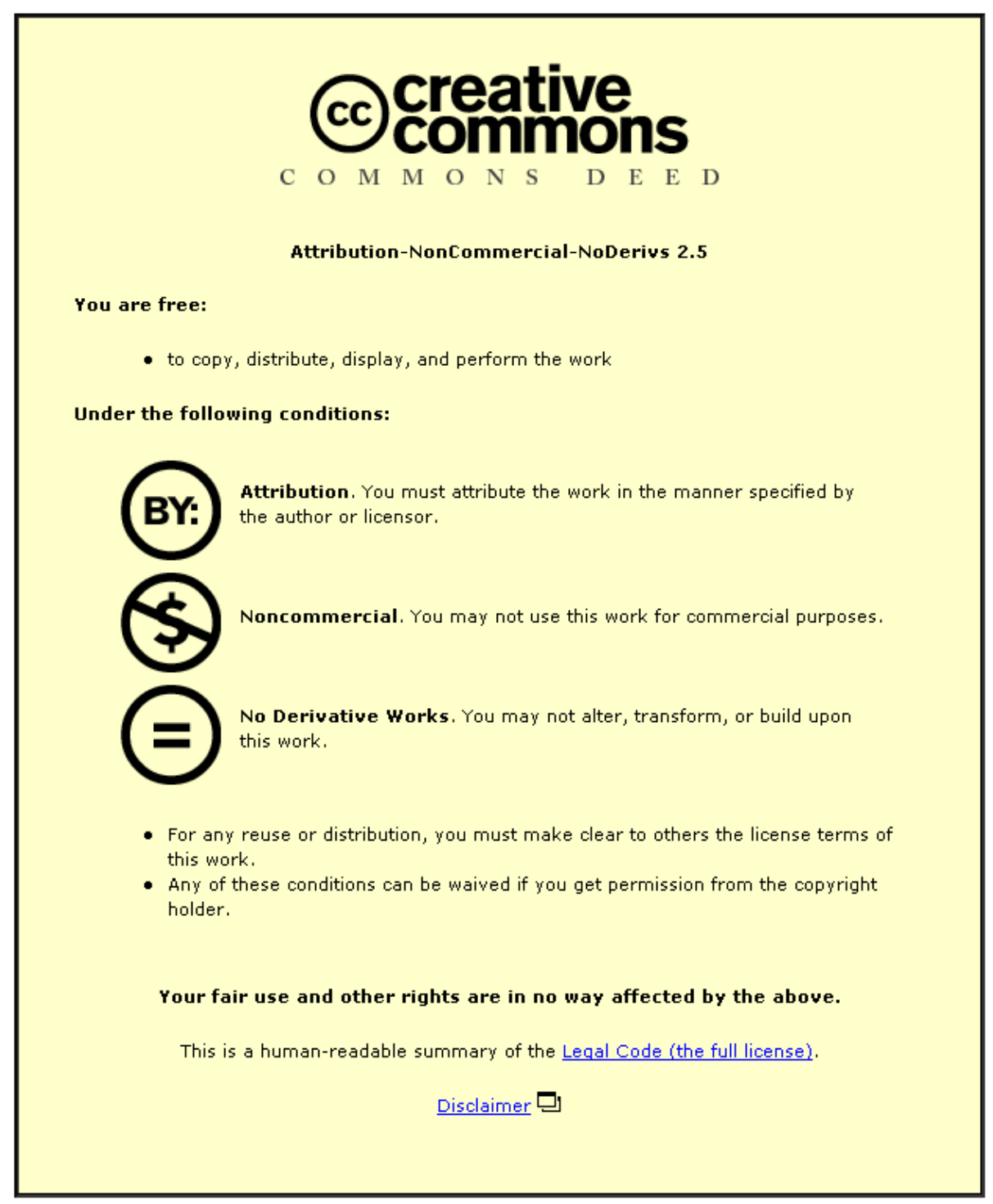

For the full text of this licence, please go to: http://creativecommons.org/licenses/by-nc-nd/2.5/ 


\title{
Maximal dismounts from high bar
}

\author{
Michael J. Hiley and Maurice R. Yeadon \\ School of Sport and Exercise Sciences, Loughborough University, Loughborough, UK
}

\begin{abstract}
In Men's Artistic Gymnastics the triple straight somersault dismount from the high bar has yet to be performed in competition. The present study used a simulation model of a gymnast and the high bar apparatus (Hiley and Yeadon, 2003a) to determine whether a gymnast could produce the required angular momentum and flight to complete a triple straight somersault dismount. Optimisations were carried out to maximise the margin for error in timing the bar release for a given number of straight somersaults in flight. The amount of rotation potential (number of straight somersaults) the model could produce whilst maintaining a realistic margin for error was determined. A simulation model of aerial movement (Yeadon et al., 1990) was used to find dismounts that would be possible with this amount of rotation potential.

The model was able to produce sufficient angular momentum and time in the air to complete a triple straight somersault dismount. The margin for error when releasing the bar using the optimum technique was $28 \mathrm{~ms}$, which is small when compared with the mean margin for error determined for high bar finalists at the 2000 Sydney Olympic Games (55 ms). Although the triple straight somersault dismount is theoretically possible, it would require close to maximum effort and precise timing of the release from the bar. However, when the model was required to have a realistic margin for error, it was able to produce sufficient angular momentum for a double twisting triple somersault dismount.
\end{abstract}

Keywords : gymnastics, high bar, simulation, angular momentum, optimisation

\section{Introduction}

The dismount from the high bar is one of the most spectacular skills performed in Men's Artistic Gymnastics. The majority of dismounts performed in elite competition comprise a double somersault with a straight (layout) body configuration with one or more twists (Figure 1). While the number of twists in the double layout somersault has increased over the years, a triple layout somersault dismount has yet to be performed in competition. On the other hand gymnasts do perform triple tucked and triple piked somersault dismounts in competition. What then are the limiting factors for dismounting with a triple layout somersault?

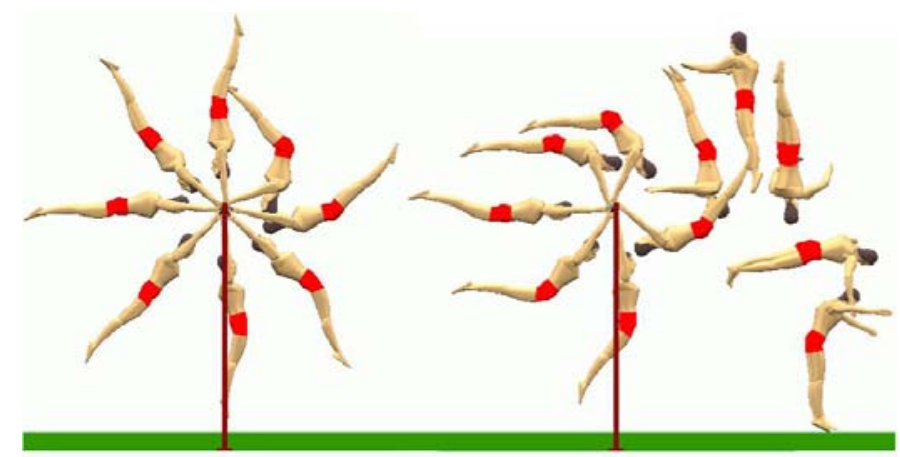

Figure 1. A double straight (layout) somersault dismount with two twists along with the preceding 13/4 backward giant circles (starting from the handstand position above the bar).

The purpose of the accelerated backward giant circle, performed prior to the dismount, is to generate sufficient linear and angular momentum by the time the gymnast releases the bar. Of the dismounts performed in elite competition it has been shown that those 
where the gymnast maintains a straight configuration for two somersaults require the greatest angular momentum (Kerwin et al., 1990; Brüggemann et al., 1994). However, in the study by Kerwin et al. (1990) one gymnast performing a triple tucked somersault dismount had comparable normalised angular momentum to one of the poorer examples of the double layout somersault dismount. Since no data has been presented on the angular momentum required to perform a triple piked somersault dismount it may be speculated that it will require more angular momentum than the double layout dismount. Perhaps the limiting factor in performing a triple layout is the gymnast's ability to produce sufficient angular momentum during the final backward giant circle.

In addition to producing angular momentum and flight, the backward giant circle can also have an effect on the sensitivity of the timing release from the bar. Hiley and Yeadon (2003b) defined the "release window" as the period of time during which the gymnast has sufficient linear and angular momentum to successfully complete the desired dismount. The release window, corresponding to twice the margin for error when releasing the bar, was determined for 11 double layout somersault dismounts from the Sydney Olympic Games and was found to have a mean of $107 \mathrm{~ms}$ (range $73 \mathrm{~ms}-157$ $\mathrm{ms}$ ). Of the two giant circling techniques identified it was found that the "scooped" technique (Figure 1) was associated with the larger release windows. It may be argued that prior to the release for a triple layout the gymnast will be rotating faster than for a double layout and this will reduce the size of the gymnast's release window since the change in the direction of mass centre velocity will take place over a shorter time. If the release window becomes too small the timing of the release becomes critical. An early release may result in insufficient time of flight whereas a late release may result in reduced angular momentum and the risk of striking the bar during flight.

The aim of this study is to determine whether it is possible for a gymnast to generate sufficient angular momentum during backward giant circles to perform a triple layout somersault dismount. The release window will be determined for the accelerated backward giant circle technique that maximises the somersault rotation in the layout position during flight in order to determine the feasibility of the dismount. If it is not possible to produce sufficient angular momentum for a triple layout with a sufficiently large release window then what dismounts are possible will be established.

\section{Methods}

A planar computer simulation model of a gymnast and high bar (Hiley and Yeadon, 2003a) was used to optimise the technique in the 13/4 backward giant circles prior to release for the dismount. The model comprised four rigid segments (arm, torso, thigh and lower leg) with the bar and the gymnast's shoulder structure modelled as damped linear springs (Figure 2). The equations of motion for the gymnast - high bar model were derived using Newton's Second Law of Motion as detailed in Hiley and Yeadon (2003a).

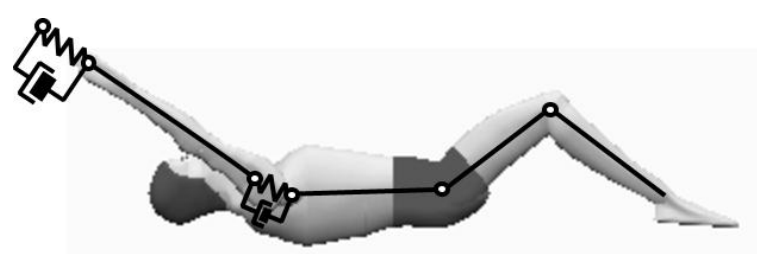

Figure 2. The four segment planar simulation model with damped linear springs representing the elastic properties of the equipment and gymnast. 
Model input comprised the segmental inertia parameters, the stiffness and damping coefficients of the bar and shoulder springs, the initial displacement and velocity of the bar, the initial angular velocity of the arm, the initial orientation of the arm, and the time histories of the shoulder, hip and knee joint angles. In changing a joint angle $\theta$, from $\theta_{1}$ to $\theta_{2}$ between times $t_{1}$ and $t_{2}$ the time history was given by:

$$
\theta(\mathrm{t})=\theta_{1}+\left(\theta_{2}-\theta_{1}\right) \mathrm{q}(\mathrm{x})
$$

where $\mathrm{x}=\left(\mathrm{t}-\mathrm{t}_{1}\right) /\left(\mathrm{t}_{2}-\mathrm{t}_{1}\right)$ and $\mathrm{q}(\mathrm{x})=\mathrm{x}^{3}\left(6 \mathrm{x}^{2}-15 \mathrm{x}+10\right)$.

Note that $\mathrm{q}(\mathrm{x})$ is the unique quintic function with the properties $\dot{\mathrm{q}}(0)=\dot{\mathrm{q}}(1)=\ddot{\mathrm{q}}(0)=\ddot{\mathrm{q}}(1)=0, \mathrm{q}(0)=0$ and $\mathrm{q}(1)=1$ so that angle changes are effected with zero velocity and acceleration at the endpoints. To avoid joint angle time histories that correspond to joint torques that exceed the strength of a gymnast, strength parameters were determined by measuring joint torques during eccentric-concentric trials using an isovelocity dynamometer for a National Team gymnast and fitting a function which expressed maximum torque in terms of joint angle and angular velocity (King and Yeadon, 2002; Yeadon and King, 2002). The joint torque functions were scaled to individual competitors using body mass (Zatsiorsky, 1995). Inertia parameters were calculated from the mean anthropometric measurements taken on seven elite gymnasts and were scaled using segment lengths of individual competitors calculated from video analysis of Olympic performances using the inertia model of Yeadon (1990). For the maximising of the somersault rotation in the straight position the inertia and strength parameters were scaled to the Olympic high bar champion. Spring parameters were calculated using static loading measurements for initial bar stiffness estimates followed by optimisation using giant swing data (Hiley and Yeadon, 2003b).

Output from the model comprised the time histories of the horizontal and vertical bar displacements, the location and velocity of the mass centre of the model, the rotation angle, the joint torques and the angular momentum of the body about its mass centre. The rotation angle during bar contact was defined as the angle between the vertical and the line joining the mass centre of the gymnast model to the neutral bar position. The angular momentum of the model about its mass centre was calculated using the equation:

$$
\mathrm{h}=\sum_{\mathrm{i}=1}^{4}\left(\mathrm{I}_{\mathrm{i}} \dot{\phi}_{\mathrm{i}}+\mathrm{m}_{\mathrm{i}}\left(\dot{\mathrm{Z}}_{\mathrm{i}} \mathrm{X}_{\mathrm{i}}-\dot{\mathrm{X}}_{\mathrm{i}} \mathrm{Z}_{\mathrm{i}}\right)\right)
$$

where $\mathrm{X}_{\mathrm{i}}=\left(\mathrm{x}_{\mathrm{i}}-\mathrm{x}_{\mathrm{cm}}\right), \mathrm{Z}_{\mathrm{i}}=\left(\mathrm{z}_{\mathrm{i}}-\mathrm{z}_{\mathrm{cm}}\right),\left(\mathrm{x}_{\mathrm{cm}}, \mathrm{z}_{\mathrm{cm}}\right)=$ whole body mass centre location, $\left(\mathrm{x}_{\mathrm{i}}, \mathrm{z}_{\mathrm{i}}\right)$ = individual segmental mass centres, $\mathrm{m}_{\mathrm{i}}=$ segmental masses, $\mathrm{I}_{\mathrm{i}}=$ segmental moments of inertia and $\dot{\phi}_{\mathrm{i}}=$ segmental angular velocities. The angular momentum was normalised by dividing by $2 \pi$ times the moment of inertia of the body about its mass centre when straight and multiplying by the flight time to give the equivalent number of straight somersaults that could be performed in the subsequent flight phase. The time of flight was calculated from the release and landing heights of the mass centre and the vertical velocity at release using the equation for constant acceleration under gravity. The model has been evaluated previously using video and force data obtained from the analysis of accelerated backward giant circles (Hiley and Yeadon, 2003a).

The simulation model was implemented with the Simulated Annealing algorithm (Goffe et al., 1994), which was used to manipulate the parameters that defined the joint angle time histories of the hip and shoulder joints. The simulations performed during the optimisation procedures started with the mass centre of the model directly above the neutral bar location (rotation angle of $0^{\circ}$ ) and with linear and angular momentum taken from video analysis of the Olympic high bar champion (Hiley and Yeadon, 2003b). The 
simulation of the bar contact phase ended once the model had rotated through $650^{\circ}$. There were four phases in each simulation during which the angles were allowed to change. These corresponded to successively opening, closing, opening and finally closing where opening involved hip extension and shoulder flexion and closing involved hip flexion and shoulder extension. For simplicity the model kept the knee joint fully extended throughout. The optimisation algorithm manipulated the magnitude and the start and end times of the actions at the hip and shoulder joints in order to maximise the release window. The release window was defined as the period of time for which the model possessed a specified minimum amount of angular momentum, landed with the mass centre between $1.4 \mathrm{~m}$ and $3.4 \mathrm{~m}$ from the bar and had a time of flight of at least 1.2 s. The limits placed on the distance travelled by the mass centre were obtained from the mean landing distances of the eight high bar finalists at the Sydney Olympics, allowing 1 $\mathrm{m}$ on either side. The lower limit on the time of flight was chosen to give a realistic dismount based on the mean flight time of $1.24 \mathrm{~s}$ of the eight Olympic finalists. Penalties were imposed for joint angle time histories, which exceeded the maximum joint torque possible at each joint angle and angular velocity. For a given joint angle and angular velocity the joint torque function was used to estimate the peak joint torque which could be produced. If a joint torque produced by the simulation model exceeded the peak value, the simulation was given a penalty. The joint torque penalty was calculated from the root mean squared (rms) difference between the estimated and exceeded joint torques over the whole simulation and then squared.

The maximum release window for a double layout dismount was determined. The optimisation procedure required an initial estimate of the parameters defining the joint angle time histories. These were based on those obtained from the Sydney Olympics high bar champion (Hiley and Yeadon, 2003b) who used a "scooped" backward giant circle technique as shown in Figure 1. The upper and lower bounds for the parameters being optimised were set so that a solution similar to the gymnast's own technique would be obtained. The lower limit for the angular momentum was set at $90 \%$ of 1.65 straight somersaults per unit flight time and this was sufficient to perform a double layout somersault dismount. This value (1.65) was based on the mean normalised angular momentum of the eight high bar Olympic finalists (Hiley and Yeadon, 2003b). The joint angle time history parameters were optimised to maximise the release window.

To determine how much normalised angular momentum could be produced whilst maintaining a sufficiently large release window, the optimum joint angle time histories from the previous optimisation were used as the initial estimates for a second optimisation. The upper and lower bounds on the parameters being optimised were extended and the lower limit on the angular momentum defining the release window was increased to 1.60 straight somersaults. The process of increasing the lower limit of the angular momentum and using the solution from the previous optimisation as the initial estimate for the next release window maximisation was continued until the model had sufficient angular momentum to perform a triple layout somersault dismount (approximately 2.60 straight somersaults). In this way the release window was determined as a function of the number of straight somersaults.

The above process was repeated with maximum joint torques reduced by $25 \%$. This was done in order to determine the effect of gymnast strength on the release window for a given angular momentum. A further four optimisations were performed to establish the sensitivity of the method to the initial angular velocity of the model and the initial displacement and velocity of the bar. Optimisations were performed with the initial angular velocity of the model, obtained from video analysis, increased by $10 \%$ and also reduced by $10 \%$. This process was repeated for the initial displacement and velocity of 
the bar. The effect of these perturbations on the size of the release window would demonstrate the sensitivity of the optimisation procedure to these variables.

In order to determine the limiting dismount for a realistic release window, the release windows from the eight gymnasts in the high bar finals at the Sydney Olympic Games were re-calculated based on the reduced travel limits used in the above optimisation procedure $(1.4 \mathrm{~m}-3.4 \mathrm{~m}$ rather than $1.0 \mathrm{~m}-3.5 \mathrm{~m})$. The resulting mean release window was used to select the limiting normalised angular momentum value. The orientation and configuration angles, normalised angular momentum and flight parameters from the optimised release window were used as input to a simulation model of aerial movement (Yeadon et al., 1990). The time histories of the configuration angles during the flight phase of the dismount were manipulated to investigate possible dismounts.

\section{Results}

The mean release window for the eight Olympic high bar finalists was recalculated to be $110 \mathrm{~ms}$. The first optimisation, which maximised the release window where the lower limit on angular momentum was sufficient to perform a double layout somersault dismount, produced a release window of $187 \mathrm{~ms}$ (Table 1). As the lower limit of the angular momentum was increased the size of the maximised release window decreased (Table 1). When the lower limit on the angular momentum was sufficient to perform a triple layout dismount (2.60 straight somersaults) the maximised release window had dropped to $57 \mathrm{~ms}$. With the constraint of maintaining a sufficiently large release window (110 ms for the Olympic finalists) the model was able to produce enough angular momentum for 2.10 straight somersaults. The normalised angular momentum at the midpoint of this release window was equivalent to 2.24 straight somersaults, whilst the mean normalised angular momentum (averaged throughout the window) was equivalent to 2.20 straight somersaults.

Table 1. Maximised release windows at each of the required minimum normalised angular momentum values

\begin{tabular}{|c|c|c|c|c|}
\hline $\begin{array}{c}\text { lower limit on } \\
\text { angular } \\
\text { momentum } \\
\text { (straight saltos) }\end{array}$ & $\begin{array}{c}\text { angle at } \\
\text { start of } \\
\text { window } \\
\left(^{\circ}\right)\end{array}$ & $\begin{array}{c}\text { angle at } \\
\text { end of } \\
\text { window } \\
\left(^{\circ}\right)\end{array}$ & $\begin{array}{r}\text { release } \\
\text { window }\end{array}$ & $\begin{array}{r}\text { release } \\
\text { window } \\
\left(^{\circ}\right)\end{array}$ \\
\hline 1.49 & 577 & 641 & 64 & 187 \\
\hline 1.60 & 577 & 643 & 66 & 189 \\
\hline 1.70 & 576 & 642 & 66 & 185 \\
\hline 1.80 & 578 & 641 & 63 & 178 \\
\hline 1.90 & 579 & 633 & 54 & 155 \\
\hline 2.00 & 577 & 624 & 47 & 140 \\
\hline 2.10 & 579 & 612 & 33 & 108 \\
\hline 2.20 & 581 & 612 & 31 & 98 \\
\hline 2.30 & 585 & 610 & 25 & 83 \\
\hline 2.40 & 591 & 613 & 22 & 80 \\
\hline 2.50 & 594 & 614 & 20 & 75 \\
\hline 2.60 & 598 & 613 & 15 & 57 \\
\hline
\end{tabular}


When the optimisation protocol was repeated with the maximum strength at the hip and shoulder joints reduced by 25\%, the size of the release windows decreased (Table 2). The initial optimisation produced a release window of $186 \mathrm{~ms}$. When the lower limit on the angular momentum was increased it was found that the model was unable to produce sufficient angular momentum to perform a triple layout. With the constraint of maintaining a sufficiently large release window (at least $110 \mathrm{~ms}$ ) the model was able to produce enough angular momentum for 1.90 straight somersaults. The normalised angular momentum at the midpoint of the release window was equivalent to 1.97 straight somersaults, whilst the mean normalised angular momentum throughout the window was equivalent to 1.96 straight somersaults. If the release window were to be based on the lower limit of the range obtained from the Olympic finalists $(83 \mathrm{~ms})$ rather than the mean (110 ms) the minimum angular momentum would increase to 2.10 straight somersaults (Table 2).

Table 2. Maximised release windows at each of the required minimum normalised angular momentum values when maximum torque was reduced by $25 \%$

\begin{tabular}{|c|c|c|c|c|}
\hline $\begin{array}{c}\text { lower limit on } \\
\text { angular } \\
\text { momentum } \\
\text { (straight saltos) }\end{array}$ & $\begin{array}{c}\text { angle at } \\
\text { start of } \\
\text { window } \\
\left({ }^{\circ}\right)\end{array}$ & $\begin{array}{c}\text { angle at } \\
\text { end of } \\
\text { window } \\
\left(^{\circ}\right)\end{array}$ & $\begin{array}{c}\text { release } \\
\text { window } \\
\left({ }^{\circ}\right)\end{array}$ & $\begin{array}{c}\text { release } \\
\text { window } \\
\text { (ms) }\end{array}$ \\
\hline 1.49 & 579 & 641 & 62 & 186 \\
\hline 1.60 & 579 & 640 & 61 & 178 \\
\hline 1.70 & 581 & 633 & 50 & 156 \\
\hline 1.80 & 581 & 624 & 43 & 141 \\
\hline 1.90 & 583 & 617 & 34 & 111 \\
\hline 2.00 & 585 & 614 & 29 & 97 \\
\hline 2.10 & 587 & 612 & 25 & 86 \\
\hline 2.20 & 589 & 611 & 22 & 75 \\
\hline 2.30 & 593 & 610 & 17 & 66 \\
\hline 2.40 & 602 & 611 & 9 & 39 \\
\hline 2.50 & - & - & - & - \\
\hline 2.60 & - & - & - & - \\
\hline & & & & \\
\hline
\end{tabular}

The release configuration and parameter set from the point of mean angular momentum of the release window for the full strength torque optimisation (Figure 3) were used as the initial conditions for the simulation model of aerial movement (Yeadon et al., 1990). Given the normalised angular momentum of $2.10-2.24$ straight somersaults over the release window, the model was capable of performing a triple piked somersault dismount (Figure 3a) or a triple somersault dismount with one twist in each of the last two somersaults (Figure 3b). For the reduced strength optimisation with a $110 \mathrm{~ms}$ window the normalised angular momentum ranged from $1.90-1.99$ straight somersaults over the window and this was still sufficient for a double twisting triple somersault (Figure 3c) although the hip and knee angles were some $14^{\circ}$ smaller than in Figure 3b. 
a

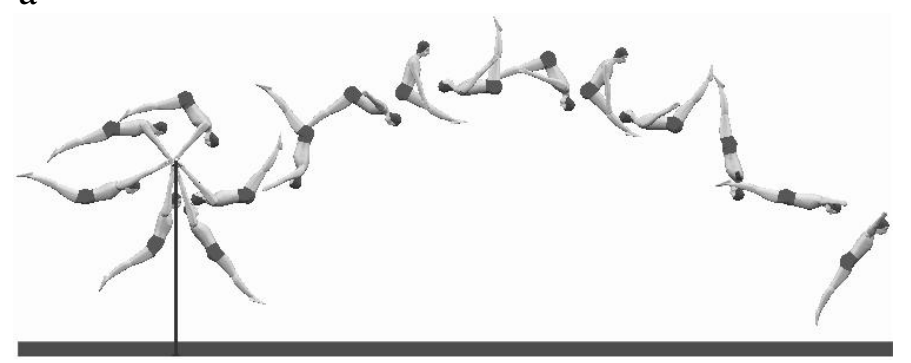

b

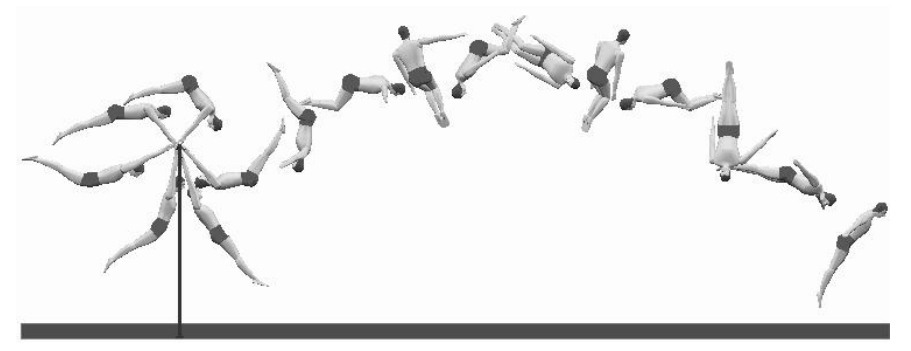

C

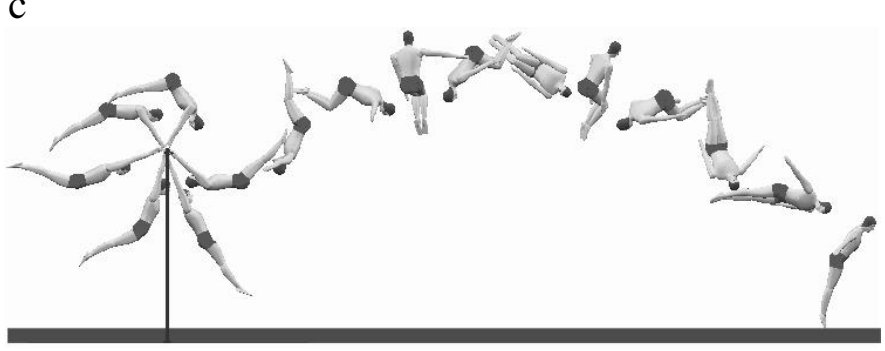

Figure 3. Limiting dismounts using optimised giant circles with full strength (a) triple piked somersault, (b) triple somersault with two twists, and with $75 \%$ strength (c) triple somersault with two twists.

The additional optimisation where the initial angular velocity of the model was increased by $10 \%$ produced a release window, at the minimum angular momentum limit of 2.10 straight somersaults, that was less than $1 \%$ different from the original optimisation. When the initial angular velocity was reduced by $10 \%$ the size of the release window was reduced by less than 3\%. The effect of varying the initial displacement and velocity of the bar produced a difference of less than $2 \%$ in the size of the optimised release window.

\section{Discussion}

The first aim of this study was to determine whether it was possible for a gymnast to perform a triple layout somersault dismount from the high bar. The second aim was to determine what difficulty of dismount would be possible if a gymnast could not perform the triple layout dismount. It was assumed that the limiting factors to performing a triple layout dismount would be the gymnast's ability to produce sufficiently large angular momentum with a sufficiently large margin for error in timing the release.

The results showed that, for the strength and inertia parameter estimates of the Olympic high bar champion, it is possible to produce sufficient linear and angular momentum for a triple layout somersault dismount. This may not be the case for all gymnasts, with their different strength and inertia characteristics. The release window for 
the triple layout dismount was small (57 ms) compared with the mean window of double layout dismounts from the Olympic finalists $(110 \mathrm{~ms})$. With such a small margin for error (28 ms, being half the release window), timing the release from the bar would be critical. Since the $28 \mathrm{~ms}$ margin is for optimal technique in the preceding giant circles, any error in circling technique would result in an even smaller margin for error. The consequence of releasing late is collision with the bar and so this movement must be considered to be of high risk.

When the maximum joint torques were reduced the model was not capable of producing sufficient angular momentum for a triple layout somersault. Therefore in order to produce sufficient linear and angular momentum for the triple layout, the gymnast must use close to maximum effort in the preceding backward giant circles. Although the triple layout is theoretically possible it is unlikely that gymnasts would perform this dismount in competition, opting instead for dismounts where they are able to work within their strength capabilities and produce consistent performances.

The second aim of the study was to determine what dismount would be possible with a realistic release window. With a release window which matched the mean of the Olympic performances (110 ms) the model was capable of producing a minimum of 2.10 straight somersaults. This was sufficient angular momentum to perform either a triple piked somersault dismount or a triple somersault dismount with two twists, as shown in Figures $3 \mathrm{a}$ and $3 \mathrm{~b}$. When the maximum joint torques were reduced the release window associated with a minimum of 2.10 straight somersaults was also reduced (86 ms). However, this was still within the range of release windows calculated from the Olympic high bar finalists (83 ms - $143 \mathrm{~ms}$ ). Alternatively, if the size of the release window were required to be larger $(110 \mathrm{~ms})$, the gymnast could still perform the triple somersault dismount with two twists, but would need to increase the angles of hip and knee flexion during flight by $14^{\circ}$ to cope with the reduced angular momentum of 1.9 straight somersaults.

The sensitivity analyses showed that variations in the initial angular velocity of the gymnast and the initial displacement and velocity of the bar had only a small effect on the size of the optimised release window. As a consequence the results of this study may be considered to be robust to such perturbations.

The present study has the limitation of being based on the inertia and strength characteristics of a single subject. Strength is based on a function fit to torque, angle, angular velocity data at each joint for a National Gymnast. Such a representation has been shown to be adequate for the simulation of tumbling (Yeadon and King, 2002), an activity in which strength is arguably more important than in high bar circling. Since the strength parameters were scaled (using only body mass) from those of a National gymnast to those of an Olympic champion, it is likely that the strength characteristics of the Olympic champion have been underestimated. A second limitation lies in the method of changing the angles at the hip and shoulder joints. The joint angle time histories were constrained to four phases of opening and closing. This is sufficient to model the general pattern of movement during the backward giant circles but is unlikely to model smaller changes accurately within this general pattern. It might be expected that using a more sophisticated representation of the joint angle time histories would lead to some increase in the size of the release windows produced. Neither of these limitations affects the conclusions that the considered dismounts are possible - only that they may be performed with a somewhat greater margin for error.

Although theoretically possible the triple layout dismount would require close to maximum effort and precise timing of the release from the bar. A gymnast performing a dismount at the end of his routine is more likely to choose a dismount where he is able to 
work within himself and more easily time the release. It has been shown that the triple somersault dismount with two twists fulfils both of these requirements. However, this dismount may not be seen in elite competition until the reward for virtuosity is increased sufficiently for it to be of benefit for the gymnast to try alternatives to the ubiquitous twisting double layout somersault dismount.

\section{Acknowledgement}

The authors wish to acknowledge the support of the British Gymnastics World Class Programme, Sport England and UK Sport.

\section{References}

Brüggemann, G-P., Cheetham, P.J., Alp, Y. and Arampatzis, D. 1994. Approach to a biomechanical profile of dismounts and release-regrasp skills of the high bar. Journal of Applied Biomechanics, 10, 291-312.

Goffe, W.L., Ferrier, G.D. and Rogers, J. 1994. Global optimisation of statistical functions with simulated annealing. Journal of Econometrics, 60, 65-99.

Hiley, M.J. and Yeadon, M.R. 2003a. Optimum technique for generating angular momentum in accelerated backward giant circles prior to a dismount. Journal of Applied Biomechanics, 19, 119-130.

Hiley, M.J. and Yeadon, M.R. 2003b. The margin for error when releasing the high bar for dismounts. Journal of Biomechanics, 36, 313-319.

Kerwin, D.G., Yeadon, M.R. and Lee, S.C. 1990. Body configuration in multiple somersault high bar dismounts. International Journal of Sport Biomechanics 6, 147-156.

King, M.A., and Yeadon, M.R. 2002. Determining subject-specific torque parameters for use in a torque driven simulation model of dynamic jumping. Journal of Applied Biomechanics, 18, 207-217.

Yeadon, M.R. 1990. The simulation of aerial movement - II. A mathematical inertia model of the human body. Journal of Biomechanics 23, 67-74.

Yeadon, M.R., Atha, J. and Hales, F.D. 1990. The simulation of aerial movement - IV. A computer simulation model. Journal of Biomechanics 23, 85-89.

Yeadon, M.R. and King, M.A. 2002. Evaluation of a torque driven simulation model of tumbling. Journal of Applied Biomechanics, 18, 295-206.

Zatsiorsky, V. 1995. Science and practice of strength training. Human Kinetics. Champaign, Ill. 